\title{
Phonological distortion as a humorous strategy in Folarin Falana's comedy skits
}

\author{
Ronke Eunice Adesoye \\ University of Ibadan, Ibadan \\ adesoyeo.ibironke@yahoo.com
}

\begin{abstract}
Various studies exist on the social functions of humour and such studies have been carried out in diverse fields that range from the humanities to the sciences. In linguistics, specifically, research shows that humour has been studied from the perspectives of syntax, pragmatics, and semantics; moreover, there is a dearth of studies on the creation of humour through phonological processes. Therefore, this study aims to investigate humour and how it is achieved using phonological processes. The study engages mainly qualitative methods of analysis. Five comedy skits were purposively selected from Folarin Falana's (Falz the Bahd Guy) eleven collections. These were chosen on the basis of their internet popularity among Nigerians; this popularity was determined on the basis of the rates of downloading the skits. McGraw \& Warren's (2010) Benign Violation Theory was used to account for the phonological violations in the comedies. The various phonological processes that were violated include liaison, deletion, insertion, monophthongisation, coalescence, and vowel strengthening. It is argued that the phonological distortions are deliberately made to achieve humour in these Nigerian comedies, especially when the high educational level of the artist is considered. Also, there anti-Anglicism and pro-Nigerianism in the data as the artist identifies himself with Nigeria(ns) and creates a niche for himself in the entertainment industry using the phonological peculiarities among Nigerians' language use, especially the Yoruba tribe. He also creates different personalities to project different messages which are not only peculiar to Nigeria but to the world, using these personalities to portray people's feelings and views of the world and how these influence their attitudes.
\end{abstract}

Keywords: phonological distortion, phonological processes, humour, Folarin Falana (Falz the Bahd Guy).

In the best comedy, there is clearly something wrong, but it is secret and understated - not even implied - comedy is the public version of a private darkness. 


\section{Background of the study}

Communication is a key aspect of human existence; it is used to maintain relationships and convey information. Its core medium is language and this manifests in different ways - it could be verbal, that is involving the use of words, or non-verbal, not requiring the use of words. In the different relationships that people share with one another, whether formal, informal, romantic, or platonic, sometimes, there are clashes, threats, misunderstandings and so on. To mitigate these, language is usually engaged tactically to restore peace and harmony. One of the ways this is done is in the area of creating humour in the forms of puns, stand-up comedy, situational comedy, practical jokes, etc. Having understood how humour remedies some negativity in the world around us, more and more comedians have risen to the occasion, making people smile and laugh despite the gloom in the atmosphere. Since the main aim of humour, whether in verbal or non-verbal language, is to expose the funny side of a situation, creativity is direly needed to achieve this. And as expected of language scholars, these strategic and creative uses of language for mitigation have attracted research and scholarship. In fact, theories have been developed to approach the analysis of humour from different perspectives.

\section{Review of previous studies}

Research on humour cuts across different fields such as linguistics, history, literature, physiology, psychology, philosophy, linguistics, sociology, literature, cognitive neuroscience, and so forth. Its interconnectedness with these disciplines has generated different theories which attempt to explain humour from these different perspectives and which perceive humour as existing for different reasons ranging from maintaining relationships to keeping societies in harmony (Mulder \& Nijholt 2002). Also, different studies exist on the social functions of humour and such studies have been carried out in diverse fields which vary from the humanities to the sciences. In linguistics, specifically, research shows that humour has been studied from the perspectives of syntax, pragmatics, and semantics; such studies include Oaks (1994), Norrick (1989), Hetzron (1991), Dolitsky (1992), Giora (2001), and Mulder \& Nijholt (2002).

Apart from its link with different fields, humour also cuts across all cultures of life and is found everywhere (Westwood \& Rhodes 2007; Sen 2012). The exact time of its emergence is not known exactly; however, according to Attardo (1994: 18), there is a common agreement that Plato is the first person who paid scholarly attention to humour. This evidently negates McGraw's (2011) claim that studies on humour began in the late 1980s. McGraw (2011) reports and disagrees with the general notion held by many that research on humour is an unserious or unworthy cause that is not worth investing in. Sen (2012) also attempts to debunk this notion about humour being an unworthy aim in research. To this end, he proposes that humour can be used as an investigative qualitative research tool which will in turn be used as a means of explaining people's cultures and social phenomena. Towards this objective, he declares the following: "Qualitative research [is] used in many of the social sciences to understand people's feelings and views about the world in which they live and how these views influence their behaviour" (Sen 2012: 3).

Linguistics is also a very thriving area through which humour has been studied by various scholars like Attardo (1994), Lew (1997), Krikmann (2006), Knight (2008), Dynel (2009), Attardo et al. (2013), Filani (2017) among others. These have considered humour from areas such as pragmatics, systemic functional linguistics, phonology, and so on. Although there are some humour studies on phonology, only a few aspects have enjoyed scholarly attention and 
this attention has been mainly on the prosody of irony (Attardo et al. 2013). These studies on the prosody of irony have shown that the recurring factor for signalling irony is found in the intonation of an utterance, whether it is flat or low. In view of this, the current study aspires at being an addition to the present literature on phonology and humour as it opens a novel area in the relationship between the two disciplines. It shows that beyond intonation, phonological processes can also be used to achieve humour in human verbal communication.

The use and function of humour, especially jokes, have also been considered deeply by Servaite (2005). In this study, he investigates how jokes can be used to better teach and learn foreign languages. He recognises the fact that linguistic jokes in English can be made at different levels ranging from phonetics to idiomatic levels. Also, he reveals that linguistic jokes possess an underlying principle of ambiguity where a misinterpretation of the linguistic unit causes the humorous effect intended. Further, he says humour studies "can be, and have been, used to test the perception of ambiguity in children, thus contributing to research on language acquisition and development" (Servaite 2005: 124). It is important to note here that language learners have not completely mastered all the aspects of the language, hence they may not comprehend as a joke what a native speaker who understands both the language and situation would.

In addition to Servaite's work (2005), Lew (1997) has a similar thing to say. He dwells extensively on linguistic jokes where he draws an interesting distinction among lexical jokes, syntactic jokes, phonological jokes, orthographic jokes, jokes of deictic reference, pragmatic ambiguity, and a few others. A recurring factor for humour among these types of jokes is the different manifestations of ambiguity which engenders humour among readers (and/or listeners). This reinforces the need for creativity in the use of language for the creation of humour. A comic artist is compelled to engage every form of language tool at their disposal to ensure that their stunts are not predictable and, as emphasised by Servaite (2005), the lexis, phonology, orthography, deictic reference, and pragmatics of any language are available to create different types of humour. This authenticates the current study, providing it with the needed platform to project the possibility and actual deployment of phonology for the achievement of humour.

Towards describing humour, Sen (2012: 1) states that "humour primarily consists of jokes (spoken or written words) and actions (describable through words); these elicit laughter or generate merriment". He admits that there is no universal or all-encompassing definition of humour and that neither is there a single theory that entirely explains all the workings of humour. He, however, discusses four theories of humour which are common in the literature; these include the relief theory, the superiority theory, the incongruity theory, and the comprehension-elaboration theory. While Sen's (2012) description limits humour to jokes and actions that elicit laughter, Attardo (2011: 135) reports that humour covers "anything that is (or may) be perceived as funny, amusing or laughable". Whichever way humour is described, there is one main criterion that cuts through all descriptions and this is laughter (Attardo 1994).

In addition to Sen's (2012) attempt to give credence and purpose to researches on humour, Clarke (2017) explores the different benefits of humour to people's health. He explores five ways through which humour helps to reduce stress and anxiety. First, it distracts people from their worries, hence reducing the physical manifestation that stress and anxiety have on the body. It also introduces a lighter edge to otherwise huge problems, thus influencing people to view their challenges in a new light which minimises it. Third, Clarke (2017) reports that humour engenders "a chemical reaction that is a powerful antithesis to stress and anxiety". Through laughter which humour generates, hormones which work against depression are produced and an individual is raised out of gloom. Finally, he states that humour heals rifts and disagreement because it encourages and smoothens out communication. 
In line with the benefits of humour, health-wise, McGraw (2011) also states that humour is physiologically beneficial and that it helps people deal with pain. It helps to cope with stress and adversity. He submits that through academic research in the field, people can be helped to live better lives - lives free of pain and stress as humanly possible. Whipple \& Calvert (2008) also report the case of Norman Cousins, a medical doctor, who revealed in his book, Anatomy of Illness (1979), how he eased a painful treatment of an incurable disease through laughter. The reports show that laughter normalises blood pressure, reduces the hormones related to stress, strengthens their immune system, relaxes the muscles, helps forget pain, stimulates learning, cleanses the lungs and the body by extension, and perhaps also protects an individual against heart attack. This report also states that laughing is a good form of exercise for the body, and can lower stress, reduce anger, and reunite people.

Central to the current study and to linguistics generally is the function that humour performs in healing rifts and disagreements by encouraging and smoothening out communication.

\section{Statement of the problem}

Considering the foregoing, therefore, it becomes obvious that humour has been studied from various perspectives, one of which is linguistics (Oaks 1994; Norrick 1989; Hetzron 1991; Dolitsky 1992; Giora 2001; Mulder \& Nijholt 2002). However, it is apparent that there are not enough studies on the phonology of comedy; it is safe to say that the only area that has attracted some attention is intonation through studies on the intonation of irony. Apart from intonation, there are many other areas in phonology that are still open to and serve as fertile ground for research. This is emphasised by Lew (1997) when he states that he sees "no immediately obvious reason why recognising phonetic non-identity should be limited to the segmental make-up of a given fragment of the joke". He continues that "suprasegmental properties, such as pitch variation, stress placement, and relative timing (rhythm) are all no less phonetically real (though perhaps less exhaustively researched and described in the phonetic literature" (Lew 1997: 135). Clearly, when the other areas in phonology are considered, for instance, the segmental level, stress, syllabification, rhythm, phonological processes and so forth, it becomes obvious that humour has not been very well researched in relation to these areas, hence there exists a call for research. This void in scholarship yearns for attention, especially in some of the available comedy skits in Nigeria which have been used as data for this study. Therefore, this study aims to investigate how humour is achieved through the manipulation of phonological processes in comedy skits from Folarin Falana, a Nigerian comedian.

\section{Research aim and objectives}

The aim of the study is to discover how phonological processes have been used to create humour in the selected skits. The objectives include:

1. to discover the phonological processes used in these skits,

2. to find out how these processes have created humour, and

3. to discuss the socio-cultural implications of the phenomena. 


\section{Theoretical framework}

\subsection{Benign violation theory}

Benign Violation Theory (henceforth BVT) was propounded by McGraw \& Warren (2010). It is a modification of Tom Veatch's Violation Theory of Humour (1998; see McGraw \& Warren 2010). The theorists hold that humour occurs when three conditions are met. These are the following:

1. a situation is violated,

2. the violation is benign, and

3. both (the first and second conditions) occur simultaneously.

This means that for humour to occur, a phenomenon that one regards as the norm or the reality is threatened, questioned, breached, or abused. However, this breach of the normalcy will be perceived as harmless and these two conditions have to occur simultaneously. In the proponents' exact words, "a situation must be appraised as a violation, a situation must be appraised as benign, and these two must occur simultaneously" (McGraw \& Warren 2010: 1142). The combination of these three conditions is what BVT regards as the sources of humour. These "violations take many forms ranging from tickling and play fighting to the violations of linguistic norms, conventions, and rules that take place in puns" (Westwood \& Rhodes 2007: 55). A situation is said to be benign when it "is non-serious, safe and playful; it is essentially the opposite of a violation" (Westwood \& Rhodes 2007: 55).

Humour is found in different aspects of human activities, as well as in linguistics. McGraw and Warren (2010: 1142) confirm this when they aver that

as humans evolved, the situations that elicited humour likely expanded from apparent physical threats to a wider range of violations, including violations of personal dignity (e.g., slapstick, physical deformities), linguistic norms (e.g., unusual accents, malapropisms), social norms (e.g., eating from a sterile bedpan, strange behaviours), and even moral norms (e.g., bestiality, disrespectful behaviours).

One of the other ways a violation can be seen as benign is if it is wrong according to a particular norm but accepted according to another. Westwood \& Rhodes (2007) fault the methodology of McGraw \& Warren (2010) and seek to determine if benign violations were more likely to be humorous than non-violation scenarios. They carried out the research using the SPSS statistical software package as against the ANOVA which was used by McGraw \& Warren (2010). Westwood \& Rhodes' (2007) findings eventually corroborated what was already done by McGraw \& Warren.

McGraw \& Warren (2015) explored the hypothesis in the domain of moral violation. However, the current study sets out to explore the hypothesis in the domain of linguistics, especially in phonological violation. Linguistic norms have been regarded as areas where violation can take place to accommodate humour (McGraw \& Warren 2010). The study is also in line with Westwood \& Rhodes (2007) which has one of its aims to confirm that moral violation is a ground for humour as asserted by McGraw \& Warren (2010).

Also, these studies have focused on the audience and their reaction to the situation. However, the current study sets out to consider the situation itself: how well does it fit into the violation that has been described by various scholars? This study is also novel in a sense that this theoretical framework has not often been employed as an analytical tool in the study of linguistics, especially phonology. 


\subsection{Phonological processes}

Words said in isolation are often pronounced differently from when they occur in connected speech. In the words of Giegerich (1992), such pronounced words in citation are "idealised". Essentially, the different adaptations that speech sounds undergo in order to enable them to be more similar to their context are what are referred to as a phonological process. This phenomenon promotes the rhythm and musicality of speech among humans (Osisanwo 2012). The phonological processes relevant to the current selected data have been purposively discussed in the subsequent paragraphs. These include: assimilation, vowel reduction, epenthesis, deletion, liaison, monophthongisation, coalescence, insertion, and vowel strengthening.

Assimilation process involves a phonological transition in which a sound takes up certain features of a surrounding sound, thus becoming more similar to its environment. It can be progressive, regressive, or coalescent (Gimson 2001). It is "a process found in all languages which causes speech sounds to be modified in a way that makes them more similar to their neighbours" (Jones 2011: xvi).

The deletion process occurs when a sound disappears, that is, it is elided when it occurs in the company of some other sounds.

"When sounds which are present in words pronounced on their own, or in slow, careful speech, are not found in different style of speech", this is called elision (Jones 2011: xviii).

Insertion is a phonological process where an extra phoneme is inserted where it never existed before.

Epenthesis is when a speaker inserts a redundant sound most likely because the phonotactics of the language to which the word belongs is different from the phonotactics of the speaker's language.

Liaison is a phonological process in which the final sound of a word is connected to the initial sound of the following word to aid pronunciation.

Coalescence occurs where two sounds combine to form another because of the cohabitation of the two phonemes.

Monophthongisation is a phonological process where a diphthong is simplified and reduced to the level of a pure vowel. Often in this case, the weaker phoneme is sacrificed for the other to form a monophthong as against the diphthong, which was originally present.

Vowel strengthening is when a weak vowel, like the schwa, is strengthened and made to sound like any of the stronger vowel sounds.

\section{Methodology}

The study mainly adopts a qualitative method of analysis. For the data, five comedy skits were purposively selected from the many collections of Folarin Falana (also known as Falz the Bahd Guy). At the time of the research, the artist had published eleven collections of comedy skits. The selected skits were chosen on the basis of their popularity on the internet among Nigerians and in Nigeria. This popularity was determined based on the rate of downloading, which the skits enjoyed as compared to others by him and other comedians. McGraw \& Warren's (2010) BVT was used to elicit phonological violations in the comedy; these violations were analysed. In the analysis, a subsection has been dedicated to each process and similar instances have been discussed extensively. This has been done to aid a wholesome examination of each of the skits as against a data-by-data analysis. The skits were transcribed using the broad, phonemic transcription of the International Phonetic Alphabet and all the areas that have phonological violations have been identified and discussed. After this, the socio-cultural implications of the violations are also extensively discussed. 


\section{Folarin Falana (a.k.a. Falz the Bahd Guy)}

Folarin Falana (henceforth Falz) was born on the 27th of October 1990 to the Nigerian human activist and lawyer Femi Falana and Funmi Falana. He was called to bar in 2012 after he graduated from the Nigerian Law School, Abuja. Before this time, he had graduated with an LLB honours degree in Law from the University of Reading. He also has a career in rapping, acting, and song writing; he holds these more highly than his pastime of comedy, although he has a rich collection of comedy skits on the internet which have accrued some fame to him. He currently has a self-reliant record label called Bahd Guys Records. Even his music is a fusion of comic lyrics and contemporary hip-hop in a faux Yoruba accent. A highly ranked record label described Falz thus 'Falz's ability to maintain a thought and get his point across in 16 barz while switching accents, infusing funny punch lines and delivering all of it in a way that makes the listener follow along is nothing short of impressive" (NotJustOk 2014). This comment is a reflection of his exquisite art in comedy and the distinctive ways he goes about it, using language in very creative ways. This creativity is a distinguishing feature that maintains his relevance and his significance in the entertainment industry.

\section{Analysis}

\subsection{Phonological distortions}

The phonological processes that have been distorted to create humour in the data include liaison, deletion, insertion, monophthongisation, coalescence, vowel strengthening, and vowel strengthening.

\subsubsection{Liaison}

Liaison is a form of linking that connects the final sound (whether consonant or vowel) of a word to the beginning of the next word. It makes speaking sound more natural and fluent unlike having to enunciate one word differently and separate from the next, especially if there is no pause whatsoever. Vowel sounds may be linked to a following vowel sound; a consonant sound may be linked to a vowel sound, and a consonant sound may be linked to another consonant sound. However, it is not all the time that these connections occur; sometimes they are needless and unnecessary.

In an attempt to violate this process, Falz deliberately conjoins words that need not be joined, hence a violation; he also does this by using extraneous phonemes that never existed in the transcription of the word under examination. This engenders a word that is wrong and foreign to the English language, hence a violation. This violation, however, becomes benign because it is not a result of ignorance, especially knowing that Falz is a graduate of Law from the University of Reading. His fake and heavy Yoruba accent shows him to have taken on the personality of an illiterate Yoruba character. Hence, this wrong application of Yoruba accent is a deliberate manoeuvre of the language for the purpose of creating humour. An instance of this phonological process is found below:

/den aikæn bi on dzin trozızæz e matalov botom/

Then I can be on jean trousers as a matter of bottom (Data 1)

In the emboldened sounds and words above, liaison has taken place and an intrusive /1/ has been inserted between matter and of, where it never existed before. The liaison that ought to have occurred here is that of $/ r$ /, joining the two words, however, the comedian has violated 
this phonological condition and used an intruding /1/ instead. Another case of liaison occurs in data 4 and it is also the case of an intruding /1/. This occurs between yellow and in, between these two words. If there were to be any liaison occurring, it should be instigated by $/ \mathrm{w} /$, however, the comedian removes this and replaces it with /1/ instead, as done in data 1 cited above. This is another case of a phonological violation which is of course deliberate, hence constituting part of the different factors that bring about humour for the listeners and audience. A few more instances have been provided below:

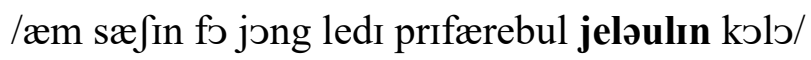

I'm searching for young lady preferable yellow in colour (Data 4)

The final cases of liaison are found in data 5 and these are also cases of an intrusive /1/:

/ai kæn mek Indomilæn frareg/

I can make indomie and fried egg (Data 5)

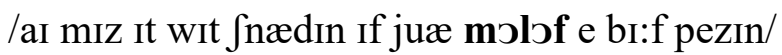

I mix it with sardine if you're more of a beef person (Data 5)

It therefore seems that all of the liaison cases in the data are cases of an intrusive $/ 1 /$; in the two examples above, there are consonant sounds that could have served as the liaison consonants that would merge the two concerned words in the two instances. However, like the previous discussed instances, an intrusive /1/ has been used to cause a benign violation again, hence humour. This form of pronunciation that has been described so far is a mispronunciation that is generally noticeable among some Nigerians; it becomes evident then that the artist has not manufactured these mispronunciations but has got them by paying attention to certain pronunciation defects of some Nigerians, especially of the Yoruba tribe. This presupposes that it is an attempt by the comedian to imitate the absurdity in the pronunciation of some Nigerians, bearing in mind that the listeners are also aware of these absurdities; both build on these knowledge to create humour.

\title{
8.1.2. Deletion
}

Deletion is also known as elision and it is a process where a sound either disappears or is not clearly enunciated in some contexts to make pronunciation easier. In relation to the data, this phonological process deals with sounds that are deliberately but inappropriately deleted in the comedian's skits. There are instances below:

\author{
/kæeua autın/ /a liz siz ida long sliv/ \\ Casual outing At least is either long sleeve (Data 1) \\ /den a kan bi on dyın trozizaz e matalovbətom/ \\ Then I can be on jeans trousers as a matter of bottom (Data 1)

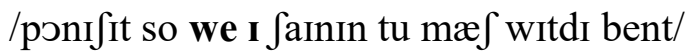 \\ punish it so wellit's shining to match with the belt (Data 1)
}

In the emboldened phonemes and words above, $/ 1, \mathrm{t}, \mathrm{s}, 1, \mathrm{ts} /$ have been deleted respectively, thus making the words sound a little confusing for comprehension. These are clearly phonological violations geared towards an attempt at humour; since the words are joined in a 
connected speech, it becomes easier to understand the deletion process in light of the whole utterance. Other instances have been randomly selected from other data; these are found below. However, data 4 has no instance of a deletion process.

/di: Is mar fjujo be/

This is my future babe (Data 2)

/boden ai nau כbsa:v dæ di fezisdæt כv eindzelinhevun/

But then I now observe that the face is that of angel in heaven (Data 2)

/mjusik wo:t/ /jumosbidzeukin/

Music what? You must be joking (Data 3)

/da:smarbəI/ /jusiarowersneurt/ /ai owersneujuwimekit/

That's my boy You see I always know it I always know you will make it (Data 3)

\section{/arkænmekındomilænfraieg/ \\ I can make indomie and fried egg (Data 5)}

The instances above have been randomly selected across different data; considering the foregoing, /s, b, t, t, t, t, 1, 1, 1/ have been deleted respectively. The recurrence of the deleted phonemes is not unnoticed; however, a closer examination reveals that the recurrence is simply a case of coincidence. The deletions in the emboldened instances are cases of violation. These may not immediately appear as a violation because of the string of connected speech that the phonemes appear in; however, with the example of /frareg/fried egg, it becomes even much easier to pronounce the words as /frardeg/, with a form of liaison taking place, than to delete the connecting consonant phoneme and pronounce the two words without it.

As in the case of liaison, deletion has been observed to be a conspicuous feature of Nigerian English. This deletion is especially found and more obvious at the syntactic level where words are elided. However, it also occurs at the phonological level, although this is not often as noticeable as words missing from sentences. A good example of deletion in Nigerian English is the case of article deletion. According to research, it has been discovered that the phonotactic structure of English and that of indigenous languages in Nigeria are quite different, and this explains certain phonological changes that English words undergo when they are produced by some Nigerians, especially those who are not well grounded in the English language. The comedian has apparently taken note of this situation and has adopted it in his comedy skits to show the common phonological violations among Nigerians and to also draw humour out of it. Hence, one can say that it is an attempt to get Nigerians to laugh at their own linguistic folly.

Another phonological violation which shows deliberateness is found in the instance of /aI כweIs neu ju wi mek It/I always know you will make it in data 3. This is a clear case of intentional violation because in such a string of speech, if any contraction were to happen, it would be that of the first two phonemes of will. However, this comedian has chosen to delete that last phoneme instead, hence showing an unlikely phonological process - a violation. All these, in addition to the level of education of the comedian, point to a single fact that ignorance is not the reason for these violations. Rather, these violations are deliberate attempts towards a major aim of exposing the linguistic practices attested among some Nigerians, and since these Nigerians (who are the audience of the comedy skits) also have a shared belief of this situation, they are able to participate in the humour that is generated. 


\subsubsection{Insertion}

Insertion is a process where an extraneous sound which was not there before gets a place in an utterance. Unlike the other phonological processes, the author does not use the insertion process very much. There is only one instance of this and it is found in data 3:

\section{/jumeinotneu it/ /du jo wokst/}

You may not know it do your worst (Data 3)

The emboldened example has $/ \mathrm{k} /$ inserted into it, hence violating the pronunciation of the word. In fact, it can be further said that the rhotic $/ \mathrm{r} /$, which is a feature of the American pronunciation, has been replaced with $/ \mathrm{k} /$ instead. So, rather than producing a possible Americanised pronunciation of the word, a wrong pronunciation is projected instead. Here, a subtle rejection of Americanism is perceived, and there is a noticeable tilt towards Nigerianism, howbeit in a peculiar way.

The scarcity of instances for this phonological violation, perhaps, is a telltale of its rarity among Nigerians. There may sometimes be instances of hypercorrectness among Nigerians, where silent letters are still pronounced. However, a case as cited above is rare, where a segment that does not even exist in the orthography of the word is introduced and pronounced. It is a rare case of mispronunciation, hence, a single manifestation in the comedy skits. This further reinforces the observation that the violations found in the data are culled from the comedian's immediate environment and locale - Nigeria.

\subsubsection{Monophthongisation}

This is a process were a diphthong is reduced to a pure vowel, that is, a monophthong. Perhaps, in an attempt to imitate how some Nigerian second language users monophthongise diphthongs because of the absence of the latter in their first languages, this comedian has chosen to do the same with some diphthongs in his skits. Instances of this phonological process have been randomly selected across the data to exemplify this feature.

/den a kæn bi on dzintrozızæz e matalovbotom/

Then $\mathbf{I}$ can be on jean trousers as a matter of bottom (Data 1)

/den mebişmtınlaikdisainafu/

Then maybe something like designer shoe (Data 1)

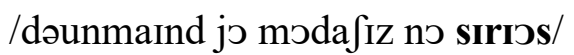

Don't mind your mother she's not serious (Data 3)

/kכntæktmi כnwכzæpfezbuk/

Contact me on whatsapp, facebook (Data 4)

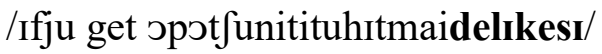

If you get opportunity to eat my delicacy (Data 5)

From the above instances, it is apparent that there are cases where diphthongs are reduced to the level of pure vowels through a deletion of one of the phonemes that ought to constitute the diphthong. These are the diphthongs which ought to be found in the emboldened words /ai, ei, Iə, eI, eI/. However, these are the pure vowels that are produced instead: /a, e, I, e, e/ where the other sounds have been deleted. According to what is usually attested in 
monophthongisation, the weaker sounds have been deleted, leaving behind the stronger sounds. These violations seem almost understandable if the only factor to be considered were to be the second language context. At this juncture, it is important to note that many Nigerian languages do not have as many vowel phonemes as there are in the English language, hence many have difficulties articulating vowel sounds. This difficulty becomes even more salient because, unlike consonant sounds, the place of articulation of vowel sounds is not as easily detectible as that of consonant sounds, hence, the challenge of pronunciation. Considering this background information, it becomes understandable that the comedian has chosen to monophthongise these diphthongs. He has been able to effectively generate humour because the listeners understand the situation surrounding the production of English vowel sounds among Nigerians. However, putting the humour factor in view, these situations then naturally combine to constitute the ground for this phonological violation.

\title{
8.1.5. Coalescence
}

"This phonological process occurs when there is a fusion of neighbouring sounds during rapid or connected speech" (Osisanwo 2012: 184). There are only two instances of coalescence in the five skits of comedy - data 4 and 5.

\author{
/kכntæktmi כn wכzæepfezbuk/ \\ Contact me on whatsapp, facebook (Data 4)

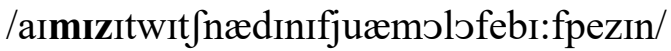 \\ I mix it with snardine if you're more of a beef person (Data 5)
}

In the two instances above, two different sounds are combined to form one; in the two cases, we have $/ \mathrm{t} /$ and $/ \mathrm{s} /$ being combined to form $/ \mathrm{z} /$, and $/ \mathrm{k} /$ and $/ \mathrm{s} /$ coming together to form /z/. These are not the acceptable pronunciations of these words; hence, not even their use in this string of words legitimates the coalescence which the comedian has committed. However, according to the theoretical framework, this violation is considered benign and the occurrence of this violation and its benign state brings about comedy for the listeners who hear the oddity in his pronunciations and utterances.

\subsubsection{Vowel strengthtening}

There are certain vowel phonemes in the English sound system that are considered to be weak. The weakest vowel sound is the schwa sound (/a/); however, because this sound is absent in most of the indigenous languages in Nigeria, many have difficulty articulating it. In the comedy skits considered, it was found that the comedian emphasised and exaggerated a mispronunciation of the schwa in the context of other sounds. This exaggeration is another attempt of violating the known norm, the reason is benign and these two conditions bring about amusement even to Nigerians who also understand the difficulty of pronouncing these weak sounds. Instances of this are cited below:

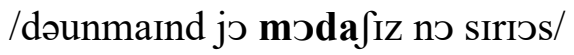

Don't mind your mother she's not serious (Data 3)

/loflırekədwondæful/

Lovely record wonderful

/fromjorubæherıæofnaidzırıæ/ 
From Yoruba area of Nigeria (Data 4)

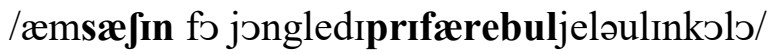

I'm searching for young lady preferable yellow in colour (Data 4)

In the instances above, the emboldened words show the strengthened vowels that the comedian uses instead of the schwa sound that he ought to have used. This replacement makes the pronunciation of the concerned words even stronger and more defined.

This phonological process is yet another extension of what is found among Nigerians on the real scene of language use. As has been said earlier, there are certain vowel phonemes that are present in the English language but absent in Nigerian indigenous languages. When Nigerians encounter challenges with pronouncing this class of phonemes, they simplify it in different ways, one of which is monophthongisation (see above). Another method is strengthening otherwise weak vowels; the schwa is a very good example of the weak vowel segment as it exists in only a few Nigerian languages. Many people have difficulty pronouncing it right; hence, they end up producing a much stronger vowel sound, hence distorting the word. The comedian has capitalised on this and used it as a means of humourcreating absurdity in his skits.

\subsection{Socio-cultural implications of the phonological distortions}

This segment of the analyses discusses the social and cultural connotations of the phonological distortions found in the data. These have been categorised into the following: identity creation and promotion of Nigerianisms.

The comedian can be said to have created a sort of identity for himself in the course of producing these comedy skits. This identity creation can be viewed from two perspectives: first, to create a niche for himself as a comedian and, second, to affirm and associate with his identity as a Nigerian. It is normal that every artist has a signature that they are known with and, since this deliberate phonological violation by Falz is found among a considerable number of Nigerians (especially Yoruba) who are illiterate, this signature can therefore be adjudged to be bi-functional. This argument is even more plausible because these skits are among the first set of videos that the young artist released early in his career. Beyond using these as a sort of trademark, it also emphasises his association with Nigeria, as it is well known that language is a very significant part of a people's culture and some of the projected violations are such that are peculiar with some Nigerians. It can then be said that he has projected a multi-faceted personality that involves him being a Nigerian and a faux illiterate person who has a bad command of language. In affirmation of what Sen (2012) says about humour explaining the culture and social phenomena of a people, Falz has successfully used his feigned Yoruba accent to portray the linguistic peculiarities of English language that hold sway in Nigeria and how these peculiarities are linked to at least one tribe or the other.

Furthermore, in the different skits used for the study, he takes on different personalities which are that of a cook, a father, a suitor, and a handsome young man talking about his wardrobe. These different characters are involved in different situations. This projects his ingenuity as expected of any comedian who wants to thrive in the industry. As a cook character, he boasts of his exemplary culinary skills, emphasising that anyone who tasted his delicacy would stick with him for a long time. As a father character, he is seen to at first discourage his son from taking up a music career, wanting him to study medicine so as to become a doctor instead. However, the tale changes when the young man (i.e. his son), makes a name for himself at his music career. The father is then seen to have fallen in love with his son's chosen career and this is portrayed by his excited inquiry into his latest album. This short 
skit is a portrayal of what generally happens between parents and their children when it comes to the choice of careers and disciplines; while parents want one thing, the children are interested in another and this brings about a clash until a compromise is reached or the choice of one party is relegated. It can be inferred, especially from the father and son characters, that these skits show people's feelings and views of the world and how these influence their attitudes.

The next character portrayed here is a young man in search of a spouse; in this skit, the character reels the features he would like in his "future babe", and these include having a fair complexion and being as well-behaved as an angel. He also mentions unrealistic expectations like having her faeces smell like strawberry. This aspect of his expectations is definitely an exaggeration, another attempt to create humour. Because of his identity creation in relation to Nigeria, another implication of these skits is that Nigerianism is promoted. It is a fact that people, especially youths, are often influenced by what they listen to and see in the media. For instance, Funke Akindele's situational comedy Jenifa's Diary, which is known for its humour creation based on ungrammaticality, has influenced people's English grammar mostly in informal contexts. It is not that these are unaware of the correct usages of the language; rather, it is only an attempt to make jokes based on their shared beliefs. The same can be said of Falz's comedy skits - it is an attempt to promote the Nigerianness in these phonological peculiarities. The availability of and accessibility to these skits on the internet even aid and encourage the influence on the youths.

The parameters mentioned above have an important implication and this is the fact that there is a subtle relationship/link between different and seemingly unconnected things in this case. Although he is a graduate of Law who has been called to bar, Falz's knowledge and command of intonation could not have prompted him to create these skits; rather, it is how he has noticed people use language. In other words, the artist is aware of the norm, he has however violated it harmlessly in order to create humour.

\section{Conclusion}

From the analysis, the various phonological processes that were violated include liaison, deletion, insertion, monophthongisation, coalescence, and vowel strengthening. It can be inferred that the phonological distortions were deliberately made to achieve humour in the data, seeing that the comedian is a highly educated individual, whose education was partly got from a reputable foreign institution. In essence, therefore, ignorance of the language is not the case here; rather, the violations are simply conscious attempts to ridicule and jest the variation of the English language spoken, especially by the Yoruba tribe, while exhorting the Nigerianness in these violations. Perhaps, it would not be too far-fetched to infer that there is antiAnglicism and pro-Nigerianism in Falz's comedy skits. This can be said to portray the linguistic peculiarities in the different tribes in Nigeria, particularly the Yoruba tribe. Also, with these skits, the comedian has created an identity for himself - both that he is Nigerian and that he uses phonological absurdities and peculiarities found among Nigerians' language use to fetch them humour. In the same vein, he creates different personalities in the skits, weaving a brief drama around them to portray certain situations which cannot really be said to be peculiar to Nigeria. He uses this to show people's perspective of the world and how this shows off on their behaviour. In other words, while using the Nigerian setting to create comedy, Falz is communicating with the world. 


\section{References}

Attardo, S. (1994). Linguistic Theories of Humour. Berlin: Mouton de Gruyter.

Attardo, S. (2011). 'Humour', in Zienkowski, J., Ostman, J., Verschueren, J. (eds.), Discursive Pragmatics, Amsterdam: John Benjamins Publishing Company, pp. 135-155.

Attardo, S., Wagner, M. M. \& Urios-Aparisi, E. (eds.) (2013). Prosody and Humour. Amsterdam/Philadelphia: John Benjamins Publishing Company.

Clarke, M. (2017). '5 ways humour reduces stress and anxiety'. Psychology of Humor, April 19, 2017. Retrieved from http://www.psychologyofhumor.com/2017/04/19/5-wayshumour-reduces-stress-and-anxiety-guest-article-by-marcus-clarke/.

Cousins, N. (1979). Anatomy of an Illness. New York: Norton.

Dolitsky, M. (1992). 'Aspects of the unsaid in humour'. Humor: International Journal of Humor Research 5(1/2), pp. 33-43.

Dynel, M. (2009). 'Beyond a joke: types of conversational humour'. Language and Linguistics Compass 3(5), pp. 1284-1299.

Filani, I. (2017). 'Politics of humour and political humour in Nigerian stand-up comedy'. Israeli Journal for Humour Research 6 (1), pp. 93-109.

Giegerich, H.J. (1992). English Phonology: An Introduction. Cambridge: Cambridge University Press.

Gimson, A.C. (2001). Gimson's Pronunciation of English. London: Arnold Publishers.

Giora, R. (2001). 'Irony and its discontent', in Schram, D.H. \& Steen, G. (eds.), The Psychology and Sociology of Literature: in Honour of Elrud Ibsch, John Benjamins Publishing Company.

Hetzron, R. (1991). 'On the structure of punchlines'. Humor: International Journal of Humor Research, 4(1), pp. 1-108.

Jones, D. (2011). Cambridge English Pronouncing Dictionary. P. Roach, J. Setter and J. Esling (eds.). Cambridge: Cambridge University Press. $18^{\text {th }}$ edition.

Knight, N. K. (2008). 'Still cool... and American too!: an SFL analysis of deferred bonds in internet messaging humour'. Systemic Functional Linguistic in Use: Odense Working Papers in Language and Communication 29, pp. 481-502.

Krikmann, A. (2006). 'Contemporary linguistic theories of humour'. Folklore. 33, pp. 27-58. [Online] http://www.folklore.ee/folklore/vol33/kriku.pdf [Accessed on 16th March, 2013.]

Lew, R. (1997). 'Towards a taxonomy of linguistic jokes'. Studia Anglica Posnaniensia 31, pp. 123-152.

McGraw, A.P. \& Warren, C. (2010). 'Benign violations: Making immoral behaviour funny'. Psychological Science, 21, pp. 1141-1149.

McGraw, P. (2011) 'The importance of humour research: a serious non-serious research topic'. Psychology today, September 14, 2011. [Online] https://www.psychologytoday.com/intl/blog/the-humor-code/201109/the-importancehumor-research. [Accessed 11th December, 2018.]

McGraw, P. \& Warren, C. (2015). 'What makes things humorous'. Proceedings of the National Academy of Sciences 112 (23), pp. 7105-7106.

Mulder, M.P. \& Nijholt, A. (2002). Humour Research: State of the Art. Enschede: Centre for Telematics and Information Technology, University of Twente.

Norrick, N.R. (1989). 'Intertextuality in humour'. Humor: International Journal of Humor Research 2(2), pp. 117-140.

NotJustOk (2014). 'The 10 most gifted rappers in Nigeria 2014: \#9 - Falz'. [Online] https://notjustok.com/features/10-gifted-rappers-nigeria-2014-9-falz/. [Accessed 23rd November, 2015.] 
Oaks, D.D. (1994). 'Creating structural ambiguities in humour: getting English grammar to cooperate'. Humor: International Journal of Humor Research 7(4), pp. 377-401.

Osisanwo, A.A. (2012). Fundamentals of English Phonetics and Phonology. Lagos: FemolusFetop Publishers.

Sen, A. (2012). 'Humour analysis and qualitative research'. Social Research Update 63. Department of Sociology, University of Surrey: Guildford, pp. 1-4.

Servaite, L. 2005. 'The anatomy of a joke'. Tiltai 4, pp. 81-85.

Theroux, P. (1989). My Secret History. New York: Putnam Adult.

Veatch, T. C. (1998). 'A theory of humour'. Humor: International Journal of Humor Research 11(2), pp. 161-215.

Westwood, R.I. \& Rhodes, C. (eds.) (2007). Humour, Work and Organisation. Abingdon, Oxon: Routledge.

Whipple, C. \& Calvert, S. (2008). 'The connection between laughter, humour, and good health'. UK Cooperative Extension Service. University of Kentucky: Health Education through Extension Leadership. 